\title{
O ESTÁGIO SUPERVISIONADO NA FORMAÇÃO DOCENTE EM QUÍMICA: Queixas que Persistem e Caminhos que Poderíamos Trilhar
}

\author{
Celio da Silveira Junior ${ }^{1}$ \\ Nilma Soares da Silva ${ }^{2}$
}

\begin{abstract}
RESUMO
O estágio curricular supervisionado é etapa importante na formação de professores e não faltam pesquisas que apontem os nós que o cercam e que sugerem possíveis caminhos para desatá-los. Utilizando o processo metodológico da análise textual discursiva, este trabalho categoriza as queixas e insatisfações manifestadas por licenciandos de Química após o desenvolvimento de seus estágios supervisionados. Em seguida, revisita parte da literatura da área para buscar subsídios que ajudem a entender as razões da persistência de manifestações dessa natureza entre os futuros professores e para delinear ações que possam enfrentá-las mais efetivamente. Conclui-se que esse quadro é motivado por razões de ordens conceitual e epistemológica, e que a sua superação passa pela reorientação dos pensares e agires não só dos professores orientadores de estágio, mas também dos supervisores, dos demais professores do curso de Licenciatura, dos licenciandos e das instituições de ensino envolvidas.
\end{abstract}

Palavras-chave: Estágio supervisionado. Formação docente. Química.

\section{SUPERVISIED INTERNSHIP IN THE CHEMISTRY TEACHER TRAINING: PERSISTENT COMPLAINTS AND PATHS THAT WE COULD TREAD}

\begin{abstract}
The supervised curricular internship is an important stage in teacher training and there is no lack of researches that point out the obstacles that surround it and that suggest possible ways to overcome such obstacles. Using the methodological process of discursive textual analysis, this paper categorizes the complaints and dissatisfactions expressed by Chemistry teaching majors after the development of their supervised internship. After that, part of the literature of this field is reviewed so as to search for data that can help understand the reasons for the persistence of this kind of manifestations among the future teachers and to delineate actions that can more effectively face them. This paper concludes that this situation is motivated by conceptual and epistemological reasons and that overcoming it involves reorienting thinking and acting, not only those of the internship advisors, but also the supervisors', the other teaching major professors', the students', and the involved educational institutions'.
\end{abstract}

Keywords: Supervised internship. Teacher training. Chemistry.

RECEBIDO EM: 2/10/2018

ACEITO EM: 19/4/2019

\footnotetext{
${ }^{1}$ Professor-adjunto vinculado à Faculdade de Educação da UFMG. Doutor e mestre em Educação (UFMG). Licenciado em Química (UFMG) e bacharel em Administração (UFMG). celiosilveirajr@yahoo.com.br

2 Professora associada do Departamento de Métodos e Técnicas de Ensino (DMTE) da Faculdade de Educação (FaE) da Universidade Federal de Minas Gerais (UFMG). Doutora e mestre em Educação e licenciada em Química (UFMG). Professora do Mestrado Profissional em Educação e Docência (Promestre/FaE/UFMG). Professora nos cursos de Especialização em Ensino de Ciências por Investigação no Centro de Ensino de Ciências e Matemática de Minas Gerais (Cecimig), na Licenciatura em Química presencial e a distância para as disciplinas de estágio e didática de ensino de Química.nilmasoares@yahoo.com.br
} 


\section{HÁ ALGO DE ERRADO COM OS ESTÁGIOS?}

O estágio curricular supervisionado é etapa importante na formação de professores. Ele se encontra, de acordo com Magrone (2012), em um ponto nervoso da formação inicial. Para o autor, estudar o estágio é estudar ao mesmo tempo o que se tem denominado de formação inicial e de formação continuada de professores. Pesquisas realizadas apontam os nós que cercam o estágio e os possíveis caminhos para desatá-los. Atuando como orientadores de estágio em um curso de formação de docentes de Química para a Educação Básica, buscamos trilhar esses caminhos. Ainda assim, ao fim de seus estágios, deparamo-nos com queixas e insatisfações dos licenciandos que não são novas, pois há muito vêm sendo relatadas pela literatura da área. Neste trabalho valemo-nos dessas manifestações dos licenciandos para, revisitando parte da referida literatura, especialmente Pimenta (1994), Maldaner (2006), Schnetzler (2008) e autores da obra organizada por Calderano (2012a, 2012b), buscarmos os subsídios que nos ajudem a entender as razões da persistência das mesmas entre os futuros professores e buscarmos delinear ações que possam enfrenta-las mais efetivamente.

\section{O CONTEXTO DE EXPLICITAÇÃO DAS VOZES DOS ESTUDANTES}

Como professores orientadores vinculados a uma Faculdade de Educação, ministramos o componente curricular Estágio de Ensino de Química III a 16 licenciandos durante o segundo semestre do ano de 2016. Entre os objetivos traçados para esse componente estava o de propiciar aos estudantes uma inserção supervisionada nas realidades de ensino de Química em escolas da Educação Básica para que eles refletissem e agissem sobre essas realidades.

Este componente curricular contava com uma carga horária de 120 horas, das quais 75 delas deveriam ser desenvolvidas no chamado campo de estágio. Nesta etapa, caberia aos estudantes, em comum acordo com os professores supervisores, planejar e desenvolver atividades variadas de ensino e de avaliação, incluindo exposições dialogadas, atividades experimentais, demonstrações, trabalhos de investigação, exercícios, atividades em grupo, etc. Como a organização dos trabalhos é pensada em torno de projetos de ensino, nesse semestre acordamos com os estagiários a utilização da mediação docente de leituras de textos didáticos de ciências nas salas de aula em que estariam inseridos. A partir disso, e dadas as nossas experiências anteriores, esperávamos que a utilização dessa abordagem resultasse naturalmente no uso de outras abordagens caras ao processo de ensino e aprendizagem de Química e que já haviam sido discutidas com esses licenciandos ao longo do curso: atividades investigativas, relação entre ciência, tecnologia e sociedade, formação e desenvolvimento de conceitos, história e filosofia da ciência, etc.

Como orientadores desses estágios buscamos participar de todo o seu desenvolvimento junto aos estudantes, desde as escolhas das escolas de atuação, os contatos com os professores supervisores, as elaborações dos planejamentos de ensino, até as avaliações de todo o processo, incluindo idas às escolas nas quais os estágios foram 
realizados. Ao final dos nossos trabalhos e discussões fizemos três questionamentos ${ }^{3}$ aos estudantes, com a intenção de captarmos, por escrito, as suas percepções sobre os estágios realizados e também sobre as suas formações docentes em geral:

1. De volta à Universidade, depois de realizado o estágio, uma questão me foi apresentada: Como foi a experiência de estágio? Muita coisa me ocorreu dizer, mas algumas são especiais e não posso deixar escapar o momento de dizê-las...

2. Se uma única sugestão minha viesse a se concretizar no curso de Licenciatura em Química dessa Universidade, eu gostaria que fosse a seguinte...

3. De tudo que aprendi em todos esses anos que aqui passei estudando para me tornar professor(a) de Química o que fica mesmo é...

\section{DAS MANIFESTAÇÕES SELECIONADAS PARA ANÁLISE}

Tínhamos uma expectativa natural de que as respostas dadas envolvessem os estágios vivenciados, a formação e o trabalho docentes, e também que expressassem uma pluralidade de sentidos, necessariamente ligados às condições contextuais de seus produtores, mas também de nós, seus receptores, todos sujeitos histórico-sociais, e, por isso, dotados de componentes cognitivos, subjetivos, afetivos e valorativos. De posse dessas respostas, buscamos fazer uma análise textual discursiva das enunciações produzidas pelos estudantes. De uma forma mais sistematizada, valemo-nos principalmente dos entendimentos de Moraes e Galiazzi (2007), segundo os quais

(...) a análise textual discursiva pode ser compreendida como um processo auto-organizado de construção da compreensão em que novos entendimentos emergem a partir de uma sequência recursiva de três componentes: a desconstrução dos textos do "corpus", a unitarização; o estabelecimento de relações entre os elementos unitários, a categorização; o captar o emergente em que a nova compreensão é comunicada e validada (p. 12).

De acordo ainda com os autores, a análise textual concretiza-se a partir de um conjunto de documentos denominado "corpus". Neste trabalho, o nosso corpus de análise foram as 48 respostas dadas pelos 16 licenciandos aos nossos três questionamentos. Feita a leitura dessas produções textuais, o primeiro elemento do ciclo de análise foi o correspondente à desmontagem dos textos. Da desconstrução dos textos surgem o que os autores chamam de unidades de análise. Assim, o processo de análise iniciou-se com a desconstrução dos textos e sua unitarização. Significou colocar o foco nos detaIhes e nas partes componentes das enunciações produzidas. Com isso, pretendeu-se conseguir perceber os sentidos desses textos em diferentes limites de seus pormenores. Isso feito, as manifestações produzidas pelos licenciandos acabaram por constituir, em suma, um mosaico de satisfações e insatisfações com o estágio, de esperanças e desesperanças com a futura profissão docente. São exemplos:

\footnotetext{
${ }^{3}$ Questionamentos adaptados dos que foram feitos em anos anteriores a outros licenciandos pela professora Maria Emília Caixeta de Castro Lima, a quem agradecemos pela cessão desses instrumentos. 
Desde o primeiro estágio tenho percebido um grande avanço em minha formação. É preciso ter contato com a prática de sala de aula para poder ganhar experiência (Estudante A).

No primeiro estágio foi um pouco amedrontador. Uma experiência totalmente nova, pois foi a primeira vez como professora em uma escola de verdade, com alunos de verdade e problemas de verdade. Ao final do Estágio 3 uma certeza: essa é a profissão pra minha vida (Estudante E).

De modo geral, gostaria de relatar a minha frustração com os três estágios que fiz. (...) O professor supervisor deve ser mais bem preparado para nos receber e identificar nossas falhas. E por fim, falta um pouco de retorno da nossa atuação (Estudante $H$ ).

Houveram alguns problemas durante o estágio, principalmente com a dificuldade de comunicação com o professor da escola. A falta de relação entre o orientador e o professor deixa o estagiário em algumas situações desagradáveis (...) (Estudante L).

Todos esses anos me mostraram como a Química é uma ciência bela e aumentou ainda mais a minha vontade de ensinar Química, para estudantes de todas as idades (Estudante M).

Essa heterogeneidade nas respostas dos licenciados pode ser atribuída a uma série de fatores, entre eles os diferentes contextos de realização dos estágios e os diferentes níveis de experiência docente apresentados pelos licenciandos. Neste trabalho voltaremos a nossa atenção para aquelas manifestações que poderiam ser entendidas como queixas e insatisfações dos estudantes com o estágio supervisionado em particular, e com a formação docente, em geral. Por que a persistência da ocorrência desse tipo de manifestação? Como poderíamos enfrentá-la? A busca de respostas a essas perguntas nos guiou na revisitação que fizemos à literatura especializada. De forma a tornar essa busca mais sistematizada, identificamos nas manifestações consideradas dos estudantes as seguintes categorias ${ }^{4}$ de queixas:

1. O estágio não prepara adequadamente para o exercício da profissão docente.

2. Falta articulação entre a Universidade e as escolas de Educação Básica.

3. A formação docente tem muita teoria e pouca prática.

4. A profissão docente é pouco valorizada.

Há claras interfaces entre essas categorias, mas, nas seções seguintes, propomos discutir mais detidamente e separadamente cada uma delas, de forma a buscar subsídios para o estabelecimento de implicações para os sujeitos e para as instituições envolvidas com a formação docente.

\footnotetext{
${ }^{4}$ Tomando por base Moraes e Galiazzi (2007), fizemos a desconstrução e unitarização de cada enunciado e agrupamos as ideias semelhantes por meio de categorias. Segundo os autores (p. 73), a categorização é um movimento de síntese que segue a unitarização, podendo encaminhar-se a partir de dois processos, um deles de natureza mais objetiva e dedutiva, e outro mais indutivo e mais subjetivo. O primeiro conduz às categorias denominadas a priori. Optamos pelo segundo processo, produzindo categorias emergentes e implicando uma construção gradativa do objeto de pesquisa.
} 


\section{O ESTÁGIO NÃO PREPARA ADEQUADAMENTE PARA O EXERCÍCIO DA PROFISSÃO DOCENTE}

Espera-se muito que os estágios supervisionados contribuam para a formação e o exercício do ofício docente. Muitas vezes esses benefícios não se materializam. Isso fica evidenciado nas seguintes manifestações dos licenciandos:

Gostaria que os estágios fossem inseridos em períodos anteriores do curso. Só temos contato com a sala de aula muito no final do curso e acredito que se iniciássemos esse contato mais cedo poderíamos ser mais bem preparados para exercer nossa profissão (Estudante $A$ ).

Honestamente, hoje estou me formando com muitas dúvidas. (...) me sinto confusa neste momento de conclusão (...) (Estudante D).

[O que fica mesmo é...] O sentimento de que ainda tenho muito a aprender. (...) Durante os estágios muitos foram os profissionais que apareceram $p /$ nos desmotivar, foi uma luta constante em busca de uma motivação (...) (Estudante $K$ ).

Existem algumas questões aprendidas nas aulas de estágio que passaram a ser de extrema importância para mim (...). Mas eu penso que existe uma distância muito grande ainda entre o que aprendemos ser uma boa aula e a nossa prática (Estudante $O$ ).

Para Pires (2012), ao estágio está sendo atribuído o papel de elo de salvação. Isso porque os cursos de Licenciatura não estariam conseguindo formar professores para dar conta da realidade do exercício do magistério. Com isso, conclui a autora, a responsabilidade do estágio fica muito grande. Para que, no entanto, servem mesmo os estágios? Concordamos com Pimenta (1994) quando afirma que a problemática a envolver os estágios tem a ver, também, com o entendimento sobre as suas finalidades e funções:

Por estágio curricular entende-se as atividades que os alunos deverão realizar durante o seu curso de formação, junto ao campo futuro de trabalho (...). Por isso costuma-se denominá-lo a "parte mais prática" do curso, em contraposição às demais disciplinas consideradas como a "parte mais teórica" (PIMENTA, 1994, p. 21).

Ainda de acordo com esta autora, à primeira vista a relação teoria e prática seria bastante simples e estaria revestida de reciprocidade e complementaridade:

A teoria investigaria a prática sobre a qual retroage mediante conhecimentos adquiridos. A prática, por sua vez, seria o ponto de partida do conhecimento, a base da teoria e, por efeito desta, torna-se prática orientada conscientemente. Essa relação de reciprocidade entre teoria e prática é uma relação onde uma complementa a outra (p. 99).

Para ela, é em razão desse entendimento que toda a responsabilidade pela prática na formação docente é atribuída às atividades de estágio. E por extensão, entendemos, é uma das razões que pode explicar o superdimensionamento de expectativas dos licenciandos em relação aos estágios quanto aos seus futuros desempenhos como professores. Caberia nos perguntarmos: O estágio é mesmo a parte principal da formação docente, e, por isso, devota-se tanto a ele um potencial sucesso ou fracasso no exercício profissional? 
Calderano (2012a) afirma que é unânime, entre os autores da obra que organiza, a compreensão de que o estágio não é a parte principal do processo de formação, mas tampouco poderia ser considerado um procedimento e componente curricular de menor importância. De acordo com Silva e Schnetzler (2008), o estágio é um momento único da vivência escolar, não podendo, porém, ser considerado um apêndice nos cursos de formação docente. Esses são entendimentos com os quais comungamos.

O estágio não deve ser o principal e nem o menos importante, um acessório. Deveria ser uma atividade articuladora do curso, um eixo integrador da formação inicial de professores. Nesse sentido, Pimenta (1994) observa que o estágio é um componente do currículo que não se configura como uma disciplina, mas como uma atividade que pode servir às demais disciplinas, tornando-se, assim, uma atividade articuladora do curso. Para Pereira e Pereira (2012), é necessária uma estreita vinculação do estágio com os demais componentes do curso de formação de professores, de forma a se caracterizar como integrador da teoria/prática e eixo nuclear. Só assim, afirmam as autoras, poderemos compreender o processo de ensino em suas dimensões histórico-social e política, bem como individual e coletiva.

Menezes (2012) também vai nessa direção de considerar a prática e o estágio como eixos estruturantes do que denomina formação prática específica do professor, advertindo-nos, porém, da necessidade que há de uma tomada de consciência do futuro professor:

Porém, consideramos que essa formação só será efetiva se for acompanhada de um processo reflexivo de conscientização do licenciando sobre o processo que o torna professor. Essa conscientização implica numa apropriação de saberes, competências e práticas próprias do fazer educativo que só se revelam na escola, no dia a dia da sala de aula, na interação com os sujeitos que constituem o espaço escolar (MENEZES, 2012, p. 218).

Vejamos que o autor aborda também uma outra importante questão. Como estamos vendo, o estágio não pode ser considerado a parte principal e nem uma parte menos importante, mas sim um eixo estruturador da formação docente. Assim, ao estágio, sozinho, não pode ser atribuído o papel de "elo de salvação" dessa formação para o exercício profissional. Isso, contudo, tampouco pode ser atribuído ao curso de formação inicial como um todo, formação essa entendida como centrada nas faculdades, universidades e institutos (MENEZES, 2012, p. 219). A formação de um professor, acreditamos, extrapola a sua fase inicial, faz-se em diversos outros tempos, espaços e movimentos.

Para Pimenta (1994), o exercício da atividade docente requer preparo, preparo esse que não se esgota nos cursos de formação. Magrone (2012) vai no mesmo sentido, defendendo que a formação de professores é um processo que só se interrompe quando se renuncia ao ofício de ensinar. Também nesse sentido, de acordo com Maldaner (2006),

(...) a formação continuada é uma necessidade intrínseca à prática pedagógica, sempre mais complexa e de nível crescente de exigência de conhecimentos da qual a formação inicial não pode dar conta. (...). No que diz respeito à formação de professores, torna-se consensual a ideia de que ela deve ser contínua e continuada, muito além da graduação específica, mesmo em nível superior, em processos insti- 
tucionalizados e de contínua avaliação, nas mais variadas formas de pesquisa e de investigação. Com isso passa-se a aceitar a idéia da complexidade da ação pedagógica em geral e da formação do professor em particular (p. 10, 17)

Diante disso tudo, podemos entender que as queixas dos estudantes em relação aos estágios, especificamente de que eles não os preparariam para o exercício da profissão docente, decorreriam da falta de uma maior compreensão sobre a função e finalidade que essas atividades formativas deveriam possuir. Quanto à concepção de que a preparação para o ofício docente extrapola os limites concernentes ao estágio, entendemos que podemos avançar mais no enfrentamento desse problema. Ainda que nós, professores orientadores de estágio, tenhamos uma maior compreensão sobre essa questão, o que é refletido nos objetivos das disciplinas/componentes curriculares que ministramos e nas discussões que fazemos com os licenciandos e com os professores supervisores de estágio, pensamos que poderíamos avançar mais ao deixarmos ainda mais explícito aos estudantes que o exercício do ofício docente vai além do estágio, vai além, inclusive, do próprio curso de formação inicial que esses estudantes estariam concluindo no momento de realização desses estágios. Uma discussão mais clara e franca com os estudantes sobre isso poderia contribuir para um enfrentamento mais crítico da questão da formação docente em seus aspectos mais gerais, inclusive quanto à requisitada função do estágio como atividade integradora do curso, discussão que esperamos fazer mais detidamente adiante neste texto.

Importante ainda destacar que, em nosso curso, temos envidado esforços no sentido de buscar uma maior integração dos professores que compõem os setores de Ensino de Química, um situado na Faculdade de Educação e o outro no Departamento de Química. Isso com o objetivo de pensarmos o curso de forma mais coletiva, especialmente quanto às chamadas disciplinas articuladoras dos conhecimentos específicos e dos pedagógicos, bem como quanto aos estágios, que buscamos tenham esse caráter essencialmente integrador tão desejado. Isso já tem surtido efeitos, em nosso entendimento: na reformatação das ementas e programas das disciplinas e demais componentes curriculares; na nossa participação no Núcleo Docente Estruturador do curso, acarretando em avanços na sua estrutura curricular; no planejamento e desenvolvimento conjunto de programas pelos professores dos dois setores de Ensino de Química; na antecipação da realização dos estágios pelos estudantes na nova estrutura curricular do curso; no aumento das disciplinas integradoras nesta estrutura; no debate mais qualificado das questões que envolvem o curso nos mais diferentes fóruns da universidade, especialmente no colegiado do curso. Ainda que os resultados dessas ações não sejam imediatos, importante é que elas demonstram que há espaços e tempos em nosso curso para a discussão e introdução das mudanças necessárias, e temos tentado ocupar esses espaços e aproveitar esses tempos.

\section{FALTA ARTICULAÇÃO ENTRE A UNIVERSIDADE E AS ESCOLAS DE EDUCAÇÃO BÁSICA}

Nas manifestações também encontramos o desejo dos licenciandos de que a Universidade se aproximasse mais da Escola Básica, e de que os professores orientadores dialogassem mais com os supervisores de estágio. Com isso haveria ganho tanto no 
planejamento quanto no desenvolvimento das ações pensadas para os estágios e para uma aproximação dos objetivos mais gerais delineados para a formação e o exercício docentes:

Outra coisa importante é o deslocamento dos professores orientadores às escolas, de maneira a observar a realidade vivenciada pelos estagiários e também verificar in loco a realidade dessas escolas (Estudante $G$ ).

As aulas de estágio (...) deveriam ter maior participação do orientador na escola e também possuir escolas credenciadas que já saibam como funciona o estágio (Estudante $L$ ).

Ao meu ver, muita coisa fica mal-entendida pelo professor da escola que nos recebe (...), tanto dos objetivos que o estagiário busca alcançar no estágio, quanto falta de informação, ou seja, má formação do professor a respeito de uma boa prática em sala (Estudante $O)$.

(...) acredito que deveria existir uma maior aproximação do professor da disciplina de estágio com o professor supervisor na escola. Muitas vezes o estágio não se processa conforme planejado porque o professor supervisor na escola não enxerga a importância do bom desenvolvimento do estágio na formação do licenciando (Estudante P).

Esse desejo dos estudantes vai ao encontro de propostas delineadas por estudiosos da questão. Magrone (2012, p. 7), prefaciando obra constituída por textos sobre o tema estágio curricular, observa que a ideia partilhada pelos seus autores é a de que 0 bom desenvolvimento do estágio curricular no interior dos cursos de formação de professores passa pelo fortalecimento progressivo da articulação entre orientador, estudantes, professores, universidades e escolas. Nesse mesmo sentido, a organizadora da obra entende que:

Também é unânime a visualização de uma tendência, frente ao estágio, de encará-lo como um trabalho coletivo que segue além do trabalho de um orientador, mas pressupõe a articulação entre os professores e entre a universidade e a escola, apoiando-se na busca de um trabalho cooperado entre alunos e professores (CALDERANO, 2012a, p. 13).

A autora entende ainda que, para isso se materializar, deveriam estar envolvidas disposições e tomadas de decisão reconhecidas e incorporadas pelas universidades, escolas, Secretarias Estaduais e Municipais de Educação. Nessa corrente vão também outros autores da obra. Para Pereira e Pereira (2012, p. 24), estágios precisam se caracterizar como parte integrante das relações escola-universidade, teoria-prática, formando um verdadeiro elo de articulação entre elas e a própria realidade. No entendimento de Pires (2012, p. 183), muitos licenciandos não veem os professores supervisores como agentes importantes do seu processo de formação, e isso, entendemos, pode ser um indicativo do que a autora aponta como sendo uma relação deficiente, a que ocorre entre universidade e escola. Para a autora, a universidade realmente não vai às escolas, distanciamento que pode ser um dos grandes dificultadores para a realização do estágio.

Ainda na citada obra, Menezes (2012) dedica-se mais detidamente ao tema, propondo um modelo colaborativo de estágio curricular supervisionado na busca de uma aproximação mais efetiva entre a universidade, as escolas e os professores envolvidos 
com o estágio. As Licenciaturas poderiam, assim, se aproximar de fato da realidade escolar, e estar-se-ia favorecendo o desenvolvimento dos saberes e competências necessários para uma prática educativa profissional. Nesse modelo, segundo o autor, professores formadores, professores em formação e professores supervisores das escolas se unem em torno de um diálogo colaborativo em prol da formação profissional prática específica do professor (p. 211). Fundamentando-se na teoria da ação dialógica de Paulo Freire, Menezes defende as interações dialógicas como meio de promover o diálogo e estabelecer uma cultura de colaboração (p. 212). Essa seria uma forma de se romper com a cultura do individualismo e do isolamento presentes na concepção da profissão docente e na forma como o estágio vem geralmente se organizando, completa o autor. Ele nos alerta, porém, que a instauração dessa colaboração dependeria muito da qualidade das interações a serem estabelecidas, entre escolas e universidade, entre os sujeitos professores, além da superação de diversos outros obstáculos, que teriam relação com as resistências inerentes à concepção da formação docente, ao entendimento da importância do estágio supervisionado, reconhecimento do trabalho dos professores supervisores.

Como estão hoje, enfatiza Menezes (2012), as atividades de estágio, concebidas na universidade e desenvolvidas nas escolas, não conseguem promover uma ação dialógica verdadeira. É com esse tipo de ação que há chances de se promover mudanças significativas na prática educativa, defende. Caso contrário, o risco na efetivação de um processo de "cima para baixo" está na violência de seu antidiálogo

(...) que impõe ao professor escolar o mutismo e a passividade. Que não reconhece sua contribuição na trans(formação) do licenciando. Que não oferece oportunidade para o licenciando desenvolver a consciência crítica, que liberta e possibilita ir além. Que não permite ao professor formador reconhecer a distância que o separa da realidade escolar (MENEZES, 2012, p. 230)

Como professores orientadores de estágio, também acreditamos na importância de uma construção coletiva para uma reflexão na e sobre a prática [que] tem um papel preponderante no processo de conscientização que nos torna professores e professoras (MENEZES, 2012, p. 217). Apoiando-nos na exotopia de Bakhtin (2011), entendemos que são os outros que nos complementam, justamente naquilo que nos seria inacessível. Assim, é na elaboração conjunta de planos, no desenvolvimento partilhado das ações e na socialização das reflexões sobre as lições vividas que todos crescemos com o processo. Acreditamos, pois, na importância do social na constituição dos sujeitos. Como, no entanto, materializar uma proposta de aproximação efetiva da universidade com as escolas da Educação Básica, de forma a atender aos anseios tanto nossos quanto dos estudantes e contribuir para a formação de todos os envolvidos?

Para Calderano (2012b), dentro de uma concepção de "docência compartilhada", um caminho seria o da criação e consolidação de grupos de estudos constituídos por alunos em formação e por professores da universidade e das Escolas Básicas. Maldaner (2006) vai no mesmo sentido, propondo a criação de dois espaços novos na formação de professores de Química, mas que poderiam ser postos em prática em qualquer curso. O primeiro deles seria localizado no interior das universidades e constituído por um núcleo de pesquisa em Educação Química, reunindo instâncias diferentes e res- 
ponsáveis pela formação docente, como os Institutos de Ciências Exatas e as Faculdades de Educação. O segundo espaço seria constituído a partir da criação de Núcleos de Pesquisa e Estudos Dentro das Escolas, nos quais:

Professores de escola seriam estimulados a se organizarem na forma de estudo e reflexão, como parte de atribuição de seu tempo de trabalho. Professores de Química da universidade, especialistas em educação de forma geral e alunos da Licenciatura participariam desses núcleos para que pudessem ser produzidos projetos coletivos de pesquisa voltados para os problemas de ensino e a formação profissional dos professores. Essa interação entre professores (...) e alunos (...) é benéfica para todos, pois permite abordar problemas crônicos de ensino e, ainda, implementar a idéia da pesquisa como princípio educativo na prática, tanto na formação inicial quanto na formação continuada (MALDANER, 2006, p. 395).

Para o autor, a produção de conhecimento pedagógico dentro de um grupo de pesquisa na escola pode mudar as práticas pedagógicas dos professores envolvidos e servir de indicativos para a formação de novos educadores. Importante ressaltar que esse modelo proposto pelos autores aproxima-se do que atualmente temos desenvolvido na Licenciatura em Química no âmbito do Programa Institucional de Bolsa de Iniciação à Docência (Pibid) ${ }^{5}$ em nossa Universidade. E uma das manifestações de nossos licenciandos se fazia exatamente no sentido de uma desejada maior aproximação entre o modelo do Pibid e o estágio:

Acredito, apesar de não ter participado, que projetos como o Pibid (...) poderiam ser uma fonte de inspiração para aperfeiçoar o estágio (Estudante $H$ ).

Nóvoa (2016) também advoga um modelo que tem, entendemos, as premissas requeridas pelos outros autores e que estão presentes no Pibid, mas vai além, sem não antes fazer duras críticas à universidade. Para ele, a universidade apresenta problemas: historicamente, pouco se preocupou com a Educação Básica; nunca se preocupou com a transição entre a formação e o exercício da profissão docente; quase não se importa com a formação continuada e as pesquisas que faz pouco têm a ver com os professores e não são feitas com eles. Questiona se as universidades vão assumir de fato os seus papeis quanto à profissão docente com o mesmo compromisso que se tem com os estudantes das Faculdades de Medicina e de Engenharia. E responde que sim, que seria possível, caso fosse adotada uma Perspectiva de Formação em Residência Docente. Para tanto duas condições deveriam ser asseguradas: 1) haver um lugar dentro da universidade (não é algo físico, arquitetônico, um prédio) que agregasse todos aqueles que queiram dedicar-se à missão de formar professores; 2) esse lugar não deveria reproduzir a lógica universitária, devendo ter a presença de universitários, professores, escolas, pesquisadores, etc.

\footnotetext{
5 De acordo com o site da Capes, fundação do MEC, o Pibid é uma iniciativa para o aperfeiçoamento e a valorização da formação de professores para a Educação Básica. Os projetos devem promover a inserção dos estudantes no contexto das escolas públicas desde o início da sua formação acadêmica para que desenvolvam atividades didático-pedagógicas sob orientação de um docente da Licenciatura e de um professor da escola. (disponível em http:// www.capes.gov.br/educacao-basica/capespibid/pibid. Acesso em 27 fev.2017).
} 
Para o autor, esse seria um terceiro lugar, em certo sentido o que representam os hospitais universitários para os estudantes de Medicina. Seria uma casa do conhecimento, dos professores, profissional, universitária. Uma casa comum, da formação e da profissão. Um lugar institucional e comum que seria o locus da discussão dos problemas da inserção nas escolas, da socialização, da colaboração com os outros colegas, da integração com o espaço escolar, do trabalho com a comunidade. Um lugar de convergência, ponto de ancoragem, que precisa dos outros e de seus compromissos.

Pois bem, finalizando esta seção, gostaríamos de lembrar que Silva e Schnetzler (2008) defendem a necessidade do estabelecimento de uma agenda para que os estágios se transformem em um tempo decisivo de metamorfose na formação docente. Essa agenda passaria pela definição dos papéis das escolas, dos professores da Educação Básica, dos licenciandos, e da organização dos tempos e espaços, ou seja, estamos falando de uma agenda cuja construção passa necessariamente por uma maior aproximação e melhor articulação entre universidade e escolas da Educação Básica, desejos dos nossos estudantes e dos autores revisitados. Eles apontam esse caminho como uma das soluções para os problemas que envolvem os estágios. Nós, como professores orientadores, temos consciência disso e agimos no sentido de também atingir esses objetivos, seja indicando campos de estágio onde os licenciandos encontrarão professores supervisores que conhecemos e que comungam de nossas concepções sobre a formação docente, professores esses que muitas vezes também estão diretamente envolvidos na formação docente inicial e continuada, atuando muitas vezes como nossos parceiros em diferentes projetos; seja visitando as escolas, conversando com os professores supervisores sobre as nossas intenções com as atividades formativas propostas, conhecendo o contexto vivenciado por esses professores, colocando-nos à disposição deles para o estreitamento desses contatos; seja orientando os nossos licenciandos no sentido de que as suas atividades nas escolas, as suas intervenções, as suas posturas, fossem sempre resultado de uma discussão e reflexão coletiva tanto conosco quanto - principalmente - com os professores supervisores de estágio. Nessas ações, esperamos não só estar respeitando os sujeitos envolvidos como também implicando-os na responsabilidade de participar desse complexo processo que é o da formação docente. Afinal, como afirma Bakhtin (2010, p.96, 99), não há álibi para a existência humana.

Aqui, obviamente, também entendemos que podemos avançar mais, seja dando maior visibilidade a essas nossas ações individuais e discutindo-as com os licenciandos, seja transcendendo-as. Concordando com a literatura abordada, acreditamos nos benefícios que ações mais institucionalizadas poderiam trazer. Elas se somariam aos nossos esforços e redundariam em ganhos de escala. E, em nossa Universidade, ações dessa natureza têm sido gestadas e progressivamente instituídas, contando com a nossa participação nas discussões quanto ao formato, indicação de escolas e professores que poderiam ser convidados a participar, reflexões sobre os primeiros resultados obtidos e expectativas para o futuro. Batizado de Programa de Integração do Ensino Básico com - Ensino Superior (Piebes), ele está sendo capitaneado pela Pró-Reitoria de Graduação (Prograd) da Universidade e em sintonia com a Secretaria de Educação do Estado. Em síntese, ele busca envolver todos os professores orientadores de estágio em uma atua- 
ção planejada de modo contínuo em um conjunto de escolas, articulando estágio, pesquisa e extensão. A partir de excerto da comunicação (não publicada) feita a esses professores, podemos entender mais claramente os objetivos do programa:

PROJETO Piebes 2017/18/19. (...) dentro das condições de cada Unidade da UFMG e de cada Professor Orientador de Estágio, de forma articulada com as Escolas, queremos: desenvolver bons estágios para os licenciandos, articular as ações desses estágios sempre que possível; propor atividades de extensão, atividades de formação continuada e de pesquisa. (...) estamos propondo a seleção de 40 a 60 escolas de Belo Horizonte (...), a serem indicadas pelos professores orientadores de estágio. Isto significará para os orientadores de estágio a priorização na indicação para os seus alunos estagiários das escolas do Piebes no período de três anos. Juntamente com as equipes das Escolas, estamos pensando em organizar nossas ações coletivamente, formando uma dupla de Professores da Universidade para cada três escolas (...). Nessa proposta, todos os professores que participarem indicarão com prioridade as escolas para seus alunos, assim como para seus projetos de extensão e pesquisa, pois acreditamos que gradativamente isto será possível dado o grande número de Escolas. (...) O que queremos? Qualificar os estágios dos nossos licenciandos com o contato com os professores já se mostra possível e necessário, estabelecendo-se um diálogo sobre os múltiplos aspectos que envolvem a prática de ensino. Desenvolver estudos de temas de interesse da escola e também projetos, conforme o desenvolvimento dos contatos se mostre necessário. Projetos articulados entre as áreas, tratando de questões que têm desafiado a Escola, serão fontes de formação e produção de conhecimentos.

Acreditamos, pois, nos frutos de ações institucionalizadas como as do Piebes podem trazer. Ainda que muitas questões precisem ser debatidas e equacionadas - uma delas é a da contrapartida aos professores supervisores que recebem os nossos licenciandos, nos moldes, por exemplo, do Pibid - entendemos que o caminho se faz caminhando, como consta no título da obra de Horton e Freire (2003).

\section{A FORMAÇÃO DOCENTE TEM MUITA TEORIA E POUCA PRÁTICA}

Na primeira categoria em que reunimos as manifestações dos licenciandos estivemos às voltas com dúvidas relacionadas à capacidade de exercício da profissão docente. Naquele momento eram queixas relacionadas especificamente aos estágios, mas também houve manifestações análogas, só que dirigidas de forma mais geral ao curso como um todo. Reclamações quanto à estrutura curricular e à própria concepção do curso, que poderia ser, na opinião dos estudantes, mais direcionado à Licenciatura:

[Eu gostaria] Que fosse dada mais atenção aos aspectos didáticos associados ao ensino de Química, ou seja, que a carga horária de disciplinas da educação fosse aumentada em detrimento de algumas disciplinas da Química "dura", que em nada contribuem para o trabalho do professor em salas de aula dos ensinos fundamental e médio (Estudante $G$ ).

[Eu gostaria] Que pudéssemos praticar mais. Porque diferente das outras profissões não teremos alguém nos supervisionando quando estivermos atuando, ou seja, o que não aprendemos vamos aprender sozinhos e podemos cometer muitos erros que podem permanecer ao longo de toda carreira (Estudante $H$ ). 
Eu gostaria que este curso tivesse uma grade curricular realmente voltada para a Licenciatura, que o curso nos ensinasse a dar aula, que pudéssemos trabalhar este aspecto do início ao fim do curso (Estudante $K$ ).

[Eu gostaria] (...) de termos mais matérias para o ensino de Química. Nos ensinar mais sobre aulas teóricas, dialógicas, experimentais, inclusivas, contextualizadas, etc... (...) Fica também uma sensação de que recebi muito conteúdo (ICEx) e vi muito pouca aplicação disso na minha vida acadêmica (Estudante $N$ ).

A demanda por cursos de formação de professores "mais práticos e menos teóricos" não é nova, e vem sendo apontada por estudos na área, em particular na de Educação em Química. Bonadiman e Leal (2012) argumentam que, nos grupos focais que organizaram com licenciandos de Química, uma das questões mais discutidas foram as influências do currículo na formação, em especial a relação entre teoria e prática e a relação entre Bacharelado e Licenciatura. O sentimento detectado pelos autores junto a esses estudantes é similar ao que encontramos nas manifestações expressas pelos nossos licenciandos: a de que o conhecimento da Química, característica básica do Bacharelado, é aprendido em profundidade pelos alunos, em detrimento dos saberes da formação profissional de professores. Entendem os autores que aos licenciandos, após estudar Química de modo bacharelesco, cabe o esforço de transpor didaticamente o conteúdo para o Ensino Médio.

Menezes (2012) alerta que os cursos de formação inicial de professores normalmente ocupam-se do domínio do conhecimento do ensino, deixando de lado o desenvolvimento das competências, práticas e saberes que estão no domínio do saber profissional docente. Nesse contexto, no qual o desenvolvimento sobre o conhecimento dos conteúdos conceituais estaria bem estabelecido nos cursos de formação docente, perguntamos: 1) Só eles bastam? 2) A quem caberia desenvolver o conhecimento pedagógico sobre esses conteúdos conceituais e as demais competências, práticas e saberes necessários ao exercício do ofício docente? Schnetzler (2006) e Silva e Schnetzler (2008) abordam essa questão, assim como Maldaner (2006). Para ele, a formação pedagógica acaba por não se "encaixar" sobre a base inicialmente construída nos cursos de formação:

Enquanto os professores universitários ligados aos departamentos e institutos das chamadas ciências básicas mantêm a convicção de que basta uma boa formação científica básica para preparar bons professores para o Ensino Médio, os professores da formação pedagógica percebem a falta de uma visão clara e mais consistente dos conteúdos específicos, por parte dos licenciandos, de tal maneira que Ihes permita uma reelaboração pedagógica, tornando-os disponíveis e adequados à aprendizagem das crianças e adolescentes. $O$ ensino de disciplinas que visam à formação pedagógica, como a Psicologia, Sociologia, Metodologias, Didática, Legislação e Prática de Ensino, não se "encaixam" sobre aquela "base" de ciências básicas construída na outra instância acadêmica (...) (p. 44).

Para o autor, a preocupação fundamental que se tem é com a formação nos conteúdos da Química, não importando o contexto em que eles poderiam ser significativos. No seu entendimento, com o qual concordamos, é diferente saber os conteúdos de Química, por exemplo, em um contexto de Química, de sabê-los em um contexto de mediação pedagógica dentro do conhecimento químico: ausente a perspectiva pedagó- 
gica, o professor não saberá mediar adequadamente a significação dos conceitos, com prejuizos sérios para a aprendizagem de seus alunos. Interessante registrar que esse desejo de uma formação "mais contextualizada" aparece nas manifestações de nossos licenciandos já apresentadas e também nas seguintes:

Embora o curso de Química tenha um caráter predominantemente técnico nos 7 semestres iniciais seria muito mais interessante (...), desde o início, uma abordagem do cotidiano (Estudante $E$ ).

Acredito que o curso deveria ter mais disciplinas de Química voltadas para os futuros professores, como uma Química Geral voltada para o Ensino Médio com a possibilidade de ter discussões a respeito das formas de abordagem e até mesmo de conceitos. Focar menos em matérias de nível de dificuldade alto e voltar mais para a Licenciatura (Estudante L).

Ainda para Maldaner (2006), é essa separação da formação em instâncias universitárias que tem impedido de se pensar os cursos como um "todo":

Espera-se, em uma das instâncias da universidade, que a formação pedagógica dê conta da formação prática do professor, como se fosse possível separar toda uma carga de trabalho pedagógico a que o estudante é submetido, de forma tácita ou não-intencional, em disciplinas de formação geral e de conteúdo específico dentro dos cursos das Licenciaturas, geralmente acoplados aos cursos de Bacharelado, ao menos nas grandes universidades (MALDANER, 2006, p. 44-45).

Diante desse quadro, de dissociação entre teoria e prática, como podemos pensar os cursos de formação docente em geral, e os estágios supervisionados, em particular? Como vimos, um caminho é o de se pensar o estágio como atividade integradora do curso, discussão anunciada e que esperamos retomá-la aqui. Para Pereira e Pereira (2012), é importante que o estágio se transforme em eixo de articulação entre os conteúdos dos cursos de formação e o conhecimento da realidade da sala de aula da escola básica. As autoras concordam que é preciso atribuir aos estágios um estatuto epistemológico que supere a sua tradicional redução à atividade prática instrumental. E avançam, no sentido de entender que o estágio não pode ser considerado como atividade prática, mas teórica, instrumentalizadora da práxis ${ }^{6}$ docente, ou seja, como atividade de transformação da realidade docente:

É importante que o estágio se concretize como um momento de aproximação da realidade estudada, num esforço de compreensão crítica. Esse exercício de reflexão vai supor uma inserção profunda nessa realidade, buscando identificar fatores determinantes e/ou intervenientes, e vai exigir a busca de respaldo teórico no conteúdo de todas as disciplinas do curso, articulando-as (PEREIRA; PEREIRA, 2012, p. 31).

É na obra de Pimenta (1994) que vamos encontrar um estudo mais sistemático sobre a práxis docente. Afirma a autora que, na formação de professores, há uma cisão entre teoria e prática, não sendo raro professores e alunos clamarem por "mais práti$c a$ ", uma vez que consideram os cursos "muito teóricos" (p. 52, 64). Também que essas

\footnotetext{
${ }^{6}$ Para Vázquez (1986, p. 241), práxis é atividade teórico-prática, ou seja, tem um lado ideal, teórico, e um lado material, propriamente prático, com a particularidade de que só artificialmente, por um processo de abstração, podemos separar, isolar um do outro.
} 
aspirações por "mais prática" frequentemente têm sido direcionadas ao estágio supervisionado. Nada diferente do que vimos nas manifestações dos nossos licenciandos, mais de duas décadas após os escritos citados. E a autora nos provoca com uma série de questionamentos. O que significa "prática"? Qual o conceito de prática (e de teoria) está presente na fala de professores e alunos? Como este conceito tem sido entendido e praticado nos cursos de formação de professores? Qual a influência da "prática" na formação? Os professores precisam de "mais prática" ou "mais teoria"? Ou de ambas? Ela mesma nos responde:

Quando os alunos (...) reclamam que os cursos são teóricos, é preciso ler estes reclames como denunciadores de que o curso não prepara teórica e praticamente para o exercício profissional, porque não toma como referência do seu currículo teórico (no qual se inclui o estágio) as necessidades que a escola-campo está colocando. Não se trata, portanto, de responder "com mais prática" e "menos teoria". O curso não forma adequadamente porque é fraco teórica e praticamente. Isto é, não assume a formação de um profissional para atuar na "prática social" (PIMENTA, 1994, p. 65).

Valendo-se de Freitas (1992, p. 96), Pimenta (1994) descreve que a questão não é a de aumentar a prática em detrimento da teoria ou vice-versa, e sim de adotarmos uma nova forma de produzir conhecimento no interior dos cursos de formação docente. Ela defende que o estágio não seja considerado o polo prático do curso, nem que esse último assuma o lugar da prática que o aluno exercerá quando for profissional. Ao contrário, o estágio deveria ser considerado uma atividade teórica, preparadora de uma práxis. O estágio deveria ser tido como uma aproximação à prática, consequente à teoria estudada no curso que, por sua vez, deveria se constituir numa reflexão sobre a realidade da escola e a partir dela. O curso, dessa forma, seria a teoria sobre a prática docente e se tornaria tão mais formador quanto as suas disciplinas/componentes curriculares todas tivessem como ponto de partida a realidade escolar.

O que se defende é uma visão de unidade entre a teoria e a prática, não como uma identidade, mas como uma relação simultânea e recíproca de autonomia e dependência. Teoria e prática como componentes indissociáveis da práxis (CANDAU; LELIS, 1983 apud PIMENTA, 1994, p. 67). Segundo Pimenta:

Traduzindo essa visão de unidade entre teoria e prática para a educação, afirmam as autoras que o fazer pedagógico, "o que ensinar" e "como ensinar", deve ser articulado ao "para quem" e "para que", expressando a unidade entre os conteúdos teóricos e instrumentais do currículo (1994, p. 67).

A atividade teórica, continua Pimenta (1994), é a que pode possibilitar o conhecimento da realidade e o estabelecimento de finalidades para sua transformação. Para essa transformação, porém, não é suficiente a atividade teórica; é preciso atuar praticamente. Por sua vez, a prática não fala por si mesma, exigindo uma relação teórica com ela, fechando-se assim o ciclo da indissociabilidade entre teoria e prática - como práxis. Para a autora, a atividade docente é práxis, ou, dito de outra forma, é uma atividade prática na qual está presente a unidade teoria e prática: 
A atividade docente é práxis. A essência da atividade (prática) do professor é o ensino-aprendizagem. Ou seja, é o conhecimento técnico prático de como garantir que a aprendizagem se realize como conseqüência da atividade de ensinar. Envolve, portanto, o conhecimento do objeto, o estabelecimento de finalidades e a intervenção no objeto para que a realidade (não-aprendizagem) seja transformada, enquanto realidade social. Ou seja, a aprendizagem (ou não-aprendizagem) precisa ser compreendida enquanto determinada em uma realidade histórico-social (PIMENTA, 1994, p. 83).

Pimenta (1994) conclui as suas reflexões sobre a práxis docente entendendo que tanto o curso de formação quanto o estágio não são a práxis do futuro professor, e sim são atividades teóricas de conhecimento da realidade e de definição de finalidades. São, na verdade, instrumentalizadores da práxis do futuro professor. Tratando especificamente do estágio, a autora concebe-o como uma atividade teórica de conhecimento da práxis dos professores que já estão atuando como profissionais nas escolas. Aponta-nos que um caminho para a ampliação da unidade entre a teoria e a prática no trabaIho dos sujeitos envolvidos na formação de docentes seria o da promoção da reflexão pedagógica-didática. Hoje, esta estaria precariamente presente, sendo evidência disso a maneira como o currículo da maioria dos cursos está constituído: por um somatório desarticulado de disciplinas, sem clareza de que se está formando um professor para uma dada realidade escolar (p. 186).

A reflexão na formação docente também é solução corroborada por outros autores. Para Schnetzler, apresentando a obra de Maldaner (2006), podemos aprender que é possível, que é viável a formação do professor reflexivo e pesquisador de sua própria prática:

(...) não basta ao professor ter um compromisso social, detectar as deficiências do seu ensino, as necessidades dos seus alunos. É necessário buscar a integração dos conhecimentos teóricos com a ação prática, explicitar os saberes tácitos que a embasam, num contínuo processo de ação-reflexão-ação que precisa ser vivenciado e compartilhado com outros colegas (SCHNETZLER, 2006, p. 15).

Para o próprio Maldaner (2006, p. 88), pensar o professor como pesquisador em uma prática reflexiva na ação e sobre a ação pode contribuir para a superação da dicotomia, própria da racionalidade técnica, que concebe alguns profissionais como produtores de conhecimentos e outros que o aplicam, ou seja, onde existe um distanciamento entre a teoria e a prática.

Pois bem, iniciamos esta seção registrando a demanda de nossos licenciandos por mais prática e menos teoria nos cursos de formação. Ao revisitarmos a literatura sobre o tema, constatamos que o problema não é o de mais prática e de menos teoria, ou o contrário. O que é preciso fazer é adotarmos uma nova forma de produzir conhecimento no interior dos cursos de formação docente. Isso passaria pela busca da indissociabilidade entre a teoria e a prática por todas as disciplinas/componentes curriculares do curso, por uma mudança de estatuto epistemológico geralmente atribuído aos estágios e aos cursos de formação e pelo aumento da reflexão didático-pedagógico no desenvolvimento dos cursos de formação de professores. 
Na condição de professores orientadores de estágio, entendemos que contribuímos para a realização desses objetivos almejados: seja por conta das intenções de nossas aulas, ou das discussões nelas feitas, seja por conta de nossas pesquisas e orientações de pesquisas de nossos licenciandos, seja em razão das contribuições que estamos dando ao processo de reformulação dos cursos de Licenciaturas que estão em curso no âmbito de nossa Universidade, seja ainda por conta de nossas atuações no Colegiado do Curso de Licenciatura em Química, sediado não em nossa Faculdade de Educação, mas sim no Instituto de Ciências Exatas. Também entendemos, no entanto, que podemos avançar mais, intensificando essas nossas ações, bem como discutindo mais profundamente com os nossos licenciandos essas questões que envolvem o estágio em particular, e o curso de formação docente, em geral.

\section{A PROFISSÃO DOCENTE É POUCO VALORIZADA}

Vimos até agora discutindo a formação para o exercício da profissão docente, mas são recorrentes as decepções dos licenciandos com os quais temos contato em relação à pouca valorização que esta profissão tem. Questão que também não é nova, ela também apareceu nas manifestações por escrito dos estudantes:

Dar aula é uma profissão cruel, é ter que se motivar a cada dia para não cair na rotina. Quando escolhemos uma profissão é claro que escolhemos pelo amor, mas assim como todo profissional também queremos crescer financeiramente (Estudante $\mathrm{K})$.

Ser professor vai muito além do que uma sala de aula e um quadro. Essa profissão apesar de ser pouco valorizada é uma função muito bonita e que exige muito preparo e dedicação (...). É preciso sempre se atualizar e renovar, buscando não ser levado pelo sistema (...) (Estudante L).

Que relações podemos estabelecer entre a formação docente e a pouca valorização do ofício docente? Como as reflexões que pudermos construir sobre esse problema da desvalorização do ofício podem ser revertidas a favor de mudanças na formação dos docentes? Buscando responder a essas questões revisitamos, como já vínhamos fazendo, parte de trabalhos que cuidaram dessa temática.

Para Maldaner (2006), a profissionalização do professor é requisito básico para a melhoria educativa em todos os níveis. Puentes, Aquino e Quillici Neto, em artigo de 2009, esclarecem que as pesquisas sobre profissionalização docente haviam crescido expressivamente nos últimos 20 anos, na esteira de um movimento de reivindicação do status profissional para os profissionais da educação! Por mais paradoxal que essa reivindicação possa parecer, como docentes, sabemos e sentimos as consequências da falta desse status, mas como tê-lo reconhecido? 
Para Cunha (2004 apud PUENTES; AQUINO; QUILLICI NETO (2009), o reconhecimento da condição profissional para a atividade do professor passa pela assunção da perspectiva de que a docência se estrutura sobre saberes próprios, intrínsecos à sua natureza e objetivos. Gauthier et al. (1998) já apontavam nessa mesma direção ao destacarem que a reflexão a respeito da formação de professores e da profissão docente deveria considerar o que os autores denominam como o "próprio cerne da problemática do ensino": caracterizar a natureza dos saberes subjacentes ao ato de ensinar, isto é, o conjunto dos conhecimentos, competências e habilidades que servem de alicerce à prática concreta do magistério (p. 14).

Muitos trabalhos já foram produzidos tomando como seus objetos de pesquisa esse conjunto de conhecimentos, competências e habilidades. Puentes, Aquino e QuiIlici Neto (2009) analisaram uma parte das pesquisas sobre as classificações/tipologias dos conhecimentos, saberes e competências necessários ao exercício da docência realizadas nos anos 80 em diante. Concluíram que era muito similar o significado conceitual dos termos empregados para referir-se ao conjunto de capacidades mais ou menos sistematizadas necessárias para pôr em prática a profissão de professor. Em todos os trabalhos selecionados a profissionalização da docência compunha-se de três ingredientes fundamentais, mas não suficientes: de saber, de saber-fazer e de saber-ser, apresentados na forma de saberes, de conhecimentos ou de competências.

Uma das pesquisas estudadas pelos autores correspondeu à de Gauthier et al. (1998). Aqui, nos valeremos dela para continuarmos nossas reflexões sobre a formação docente e a falta de valorização profissional da atividade docente. Para eles, ao contrário de outros ofícios que desenvolveram um corpus de saberes, o ensino tarda a refletir sobre si mesmo: mesmo que o ensino já venha sendo realizado há séculos, é muito difícil definir os saberes envolvidos no exercício desse ofício, tamanha é a sua ignorância em relação a si mesmo (p. 20). Nesse sentido, entendem como essencial refletir sobre certas ideias preconcebidas que impedem o desabrochar de um saber desse ofício sobre si mesmo e prejudicam o processo de profissionalização do ensino. Em suma, as ideias preconcebidas seriam as seguintes em relação ao ofício docente: basta conhecer o conteúdo; basta ter talento; basta seguir sua intuição; basta ter experiência; basta ter cultura.

Assim, Gauthier et al. (1998) entendem que contribuiríamos para tirar o ensino da espécie de cegueira conceitual em que se encontra. Os autores defendem que, na verdade, temos sim um ofício "feito de saberes", uma concepção segundo a qual vários saberes são mobilizados pelo professor em seu ofício: saberes disciplinares, saberes curriculares, saberes das ciências da educação, saberes da tradição pedagógica e saberes da ação pedagógica. Em suma, as descrições desses saberes e de como os professores os mobilizam e em quais sentidos seriam as constantes no Quadro 1. 
Quadro 1 - Saberes mobilizados pelo professor em seu ofício

\begin{tabular}{|c|c|}
\hline Saberes & Descrição \\
\hline Disciplinares & $\begin{array}{l}\text { Correspondem às diversas áreas do conhecimento. O professor não produz } \\
\text { o saber disciplinar, mas se vale dele para ensinar. De fato, ensinar exige um } \\
\text { conhecimento do conteúdo, visto que não se pode ensinar algo cujo conteúdo } \\
\text { não se domina. Juntamente com outros saberes, ele faz parte do reservatório } \\
\text { de saberes disponível. }\end{array}$ \\
\hline Curriculares & $\begin{array}{l}\text { A escola seleciona e organiza certos saberes produzidos pelas ciências e } \\
\text { os transforma num corpus que será ensinado nos programas escolares. O } \\
\text { professor deve, evidentemente, "conhecer o programa", que constitui um } \\
\text { outro saber de seu reservatório de conhecimentos. É o programa que lhe } \\
\text { serve de guia para planejar, para avaliar. }\end{array}$ \\
\hline $\begin{array}{l}\text { Das ciências da } \\
\text { educação }\end{array}$ & $\begin{array}{l}\text { Todo professor adquiriu, durante a sua formação ou em seu trabalho, } \\
\text { determinados conhecimentos profissionais que o informam a respeito de } \\
\text { várias facetas de seu ofício ou da educação de um modo geral: noções sobre } \\
\text { o sistema escolar, sobre a evolução da profissão, sobre o desenvolvimento da } \\
\text { criança, sobre a violência entre jovens, sobre a diversidade cultural, etc. }\end{array}$ \\
\hline $\begin{array}{l}\text { Da tradição } \\
\text { pedagógica }\end{array}$ & $\begin{array}{l}\text { É o saber dar aulas que transparece numa espécie de intervalo da consciência. } \\
\text { Cada um tem uma representação da escola que o determina antes mesmo } \\
\text { de ter feito um curso de formação de professores. Concepção prévia do } \\
\text { magistério. }\end{array}$ \\
\hline Experienciais & $\begin{array}{l}\text { A experiência do professor não deixa de ser uma coisa pessoal e, acima de } \\
\text { tudo, privada. Ele realiza julgamentos privados, elaborando ao longo do tempo } \\
\text { uma espécie de jurisprudência composta de truques, de estratagemas e de } \\
\text { maneiras de fazer que, apesar de testadas, permanecem em segredo. Nesse } \\
\text { sentido, um professor pode ter experiência e dar explicações errôneas para } \\
\text { justificar sua maneira de agir. }\end{array}$ \\
\hline $\begin{array}{l}\text { Da ação } \\
\text { pedagógica }\end{array}$ & $\begin{array}{l}\text { É o saber experiencial dos professores a partir do momento em que se torna } \\
\text { público e que é testado por meio das pesquisas realizadas em sala de aula. } \\
\text { Os saberes da ação pedagógica legitimados pelas pesquisas são atualmente o } \\
\text { tipo de saber menos desenvolvido no reservatório de saberes do professor, e } \\
\text { também, paradoxalmente, o mais necessário à profissionalização do ensino. }\end{array}$ \\
\hline
\end{tabular}

Fonte: Adaptado de Gauthier et al. (1998, p. 29).

Dado todo esse exposto, que denota com clareza a complexidade envolvida no exercício da profissão docente, nos perguntamos: As referidas ideias preconcebidas que formam o entendimento de que o ofício docente é desprovido de saberes poderiam estar, inclusive, no bojo de nossos cursos de formação docente? E assim poderiam até justificar algumas das manifestações feitas pelos nossos licenciandos? Nossas experiências, infelizmente, nos obrigam a responder afirmativamente à questão. Especificamente em relação à formação docente em Química, Schnetzler (2006) aponta a ingenuidade comum que há em se assumir a tarefa docente como um simples transmitir de informações químicas, e de que ensinar é fácil, bastando saber o conteúdo e empregar algumas técnicas pedagógicas. Esse quadro só aumenta a nossa responsabilidade em tentar desarticular essas preconcepções, seja intramuros nos cursos de formação docente ou fora deles.

\section{CAMINHOS QUE PODERIAM SER TRILHADOS}

Neste trabalho descrevemos queixas de licenciandos de Química expressas ao fim de suas intervenções nas escolas da Educação Básica e de nossas atividades e discussões na Universidade no âmbito da última etapa de seus estágios supervisionados. 
Essas queixas diziam respeito aos estágios em particular (não preparam para o ofício docente e não há articulação entre a Universidade e as escolas da Educação Básica), ao curso de formação docente em geral (tem muita teoria e pouca prática) e ao ofício docente (não é valorizado). Vimos que elas não eram reclamações inéditas, uma vez que já vinham sido relatadas por trabalhos que revisitamos. Buscamos nestas pesquisas entender as origens da persistência das manifestações e encontrar possíveis maneiras de enfrentá-las.

Concluímos que esse quadro é motivado por razões de ordens conceitual e epistemológica. Dito de outra forma, entendemos que esse tipo de manifestação tem como causa uma atribuição conceitualmente equivocada de estatutos epistemológicos para os estágios e para a formação docente como um todo. $\mathrm{E}$, em suma, poderíamos afirmar que os caminhos para enfrentar essas razões e para reverter esse quadro envolveriam a manutenção de ações que já desenvolvemos como orientadores de estágio, mas que também passariam por avanços a serem buscados pelo conjunto dos sujeitos envolvidos na formação docente:

A. Explicitar as finalidades e funções do estágio. 0 estágio não deve ser o principal e nem o menos importante, um acessório no curso de formação docente. Deveria ser uma atividade articuladora do curso, um eixo integrador da teoria/ prática da formação inicial de professores.

B. Atribuir aos estágios um estatuto epistemológico que supere a sua tradicional redução à atividade prática instrumental, considerando-o não como atividade prática, mas teórica, instrumentalizadora da práxis docente.

C. Refletir sobre a formação de um professor, que extrapola a sua fase inicial, a do curso de formação inicial, fazendo-se em diversos outros tempos, espaços e movimentos.

D. Buscar o fortalecimento progressivo da articulação entre os professores orientadores, os professores supervisores, os professores em formação (estudantes), os demais professores do curso, enfim, buscar um maior trabalho colaborativo entre as universidades e as escolas.

E. Definir claramente, no âmbito dos estágios e da formação docente, os papéis das escolas, dos professores da Educação Básica, dos orientadores, dos licenciandos e da organização dos tempos e espaços.

F. Articular estágio, pesquisa e extensão nas ações dos licenciandos junto às escolas de Educação Básica.

G. Desenvolver no curso de formação, como um todo, as competências, práticas e saberes que estão no domínio do saber profissional docente. $O$ curso se tornará tão mais formador quanto as suas disciplinas e demais componentes curriculares tiverem todos a realidade escolar como ponto de partida.

H. Não dissociar teoria e prática nos cursos de formação docente. Ter uma visão de unidade entre a teoria e a prática, não como uma identidade, mas como uma relação simultânea e recíproca de autonomia e dependência. 
I. Aumentar a reflexão pedagógica-didática no interior dos cursos de formação docente, de forma a evitar que ele se constitua como um mero somatório desarticulado de disciplinas e outros componentes curriculares, sem clareza de que se está formando um professor para uma dada realidade escolar.

J. Promover a formação de um professor reflexivo e pesquisador de sua própria prática, de forma a superar a dicotomia, própria da racionalidade técnica, que concebe alguns profissionais como produtores de conhecimentos e outros como os que o aplicam.

K. Reivindicar status profissional para os profissionais da educação. O reconhecimento desta condição para a atividade do professor passa pela assunção da perspectiva de que a docência se estrutura sobre saberes próprios, intrínsecos à sua natureza e objetivos.

As propostas que anteriormente descrevemos também não são inéditas, já tendo sido apontadas em vários outros trabalhos anteriores, no entanto a persistência de algumas manifestações de nossos licenciandos, também presentes nos referidos trabaIhos, e que podem ser um indicativo do pensamento de licenciandos de outros cursos e universidades, mostra-nos ainda mais a importância de tentarmos caminhar no sentido da promoção dessas propostas. Um caminhar que sabemos não será sem o enfrentamento de obstáculos, mas do qual não podemos nos afastar.

Por fim, em relação especificamente à formação docente em Química, e dialogando com a literatura que revisitamos, entendemos importante manter e aprimorar as nossas ações no sentido de os estágios serem pensados em termos de projetos de ensino que buscam integrar de forma articulada os conhecimentos específicos da Química e os conhecimentos pedagógicos necessários para a mediação do processo de ensino e aprendizagem na Escola Básica. Um projeto de ensino que utiliza, por exemplo, a mediação docente de textos didáticos de Química exigirá um esforço que vai além dessa abordagem ou ferramenta, sendo necessário para a sua efetiva utilização uma articulação com as didáticas, com as instrumentações para ensino, com as disciplinas, com os conhecimentos específicos, etc. Nesta proposta, os estágios servem às outras disciplinas e componentes curriculares do curso, articulando-os. Assim, entendemos, os estágios, transformados em atividades teóricas (em que teoria e prática encontram-se indissociáveis), deixam de ser apenas um cumprimento formal de requisito legal e passam a fundamentar teoricamente a atuação desse futuro docente de Química, que, assim, terá condições de transformar sua realidade.

\section{REFERÊNCIAS}

BAKHTIN, M. Estética da criação verbal. 6. ed. São Paulo: Martins Fontes, 2011.

BAKHTIN, M. Para uma filosofia do ato responsável. São Carlos: João e Pedro Editores, 2010.

BONADIMAN, H. L.; LEAL, M. C. Formação docente e currículo na perspectiva de estagiários de uma licenciatura em química. In: CALDERANO, M. A. (org.). Estágio curricular: concepções, reflexões teórico-práticas e proposições. Juiz de Fora: Ed. UFJF, 2012.

CALDERANO, M. A. Estágio curricular: formação inicial, trabalho docente e formação contínua. In: CALDERANO, M. A. (org.). Estágio curricular: concepções, reflexões teórico-práticas e proposições. Juiz de Fora: Ed. UFJF, 2012a. 
CALDERANO, M. A. O estágio curricular e os cursos de formação de professores: desafios de uma proposta orgânica. In: CALDERANO, M. A. (org.). Estágio curricular: concepções, reflexões teórico-práticas e proposições. Juiz de Fora: Ed. UFJF, 2012b.

CANDAU, V. M.; LELIS, I. A relação teoria-prática na formação do educador. Tecnologia educacional. Rio de Janeiro, (55): 12-18, nov./dez. 1983.

CUNHA, M. I. da. A docência como ação complexa: o papel da didática na formação de professores. In: ROMANOWSKI, J. P.; MARTINS, P. L. O.; JUNQUEIRA, S. R. A. Conhecimento local e conhecimento universal: pesquisa, didática e ação docente. Curitiba: Champagnat, 2004. p. 31-42.

FREITAS, L. C. Neotecnismo e formação do educador. In: ALVES, N. (org.). Formação de professores - pensar e fazer. São Paulo: Cortez, 1992. p. 89-102.

GAUTHIER, C. et al. Por uma teoria da Pedagogia. ljuí: Ed. Unijuí, 1998. p. 17-37.

HORTON, M.; FREIRE, P. O caminho se faz caminhando: conversas sobre educação e mudança social. Petrópolis: Vozes, 2003.

MAGRONE, E. Prefácio. In: CALDERANO, M. A. (org.). Estágio curricular: concepções, reflexões teórico-práticas e proposições. Juiz de Fora: Ed. UFJF, 2012.

MALDANER, O. A. A formação inicial e continuada de professores de química: professores/pesquisadores. 3. ed. ljuí: Ed. Unijuí, 2006.

MENEZES, P. H. D. Formação profissional prática específica do professor: reflexões sobre um modelo colaborativo de estágio curricular supervisionado. In: CALDERANO, M. A. (org.). Estágio curricular: concepções, reflexões teórico-práticas e proposições. Juiz de Fora: Ed. UFJF, 2012.

MORAES, R.; GALIAZZI, M. C. Análise textual discursiva. Ijuí: Ed. Unijuí, 2007.

NÓVOA, A. Perspectiva de formação em residência docente. Belo Horizonte: Faculdade de Educação da UFMG, 2016. Palestra realizada em 9 de junho de 2016. Disponível em: https://www.youtube.com/watch?v=Sm1z2JN-m20. Acesso em: 27 fev. 2017.

PEREIRA, R. C. B.; PEREIRA, R. O. O estágio supervisionado no contexto da formação de professores. In: CALDERANO, M. A. (org.). Estágio curricular: concepções, reflexões teórico-práticas e proposições. Juiz de Fora: Ed. UFJF, 2012.

PIMENTA, S. G. O estágio na formação de professores: unidade teoria e prática? São Paulo: Cortez, 1994.

PIRES, F. C. O. O papel do professor orientador na efetiva-ação do estágio: múltiplas visões. In: CALDERANO, M. A. (org.). Estágio curricular: concepções, reflexões teórico-práticas e proposições. Juiz de Fora: Ed. UFJF, 2012.

PUENTES, R. V.; AQUINO, O. F.; QUILLICI NETO, A. Profissionalização dos professores: conhecimentos, saberes e competências necessários à docência. Educar em Revista [on-line], Curitiba: Editora UFPR, n. 34, 2009. p. 169-184.

SCHNETZLER, R. P. Apresentação. In: MALDANER, O. A. A formação inicial e continuada de professores de química: professores/pesquisadores. 3. ed. ljuí: Ed. Unijuí, 2006.

SILVA, R. M. G.; SCHNETZLER, R. P. Concepções e ações de formadores de professores de Química sobre o estágio supervisionado: propostas brasileiras e portuguesas. Revista Química Nova, São Paulo: Sociedade Brasileira de Química, v. 31, n. 8, 2008.

VÁZQUEZ, A. S. Filosofia da Praxis. 3. ed. Rio de Janeiro: Paz e Terra, 1986. 